\title{
Dynamic Contact Angle Measurements
}

\author{
Omar Clarke, Jomarie Leblanc, Sheldon Walsh \\ Mentor: Dr. Mahmoud Elsharafi \\ College of Science \& Mathematics, McCoy School of Engineering
}

\begin{abstract}
One of the major problems arising in the Oil Industry is those associated with oil extraction. The ideal conditions on the rock surface should be water wet conditions, to facilitate the easy extraction of oil. Contact angle measurements are key to determine surface tension between solids and various fluids. If the rock wettability is oil wet, the oil company may need to change the rock wettability. We will determine wettability (water wet or oil wet), analyze how the effect of different brine concentrations on wettability and contact angle measurements using the Dynamic Contact Angle Analyzer (DCA 315).
\end{abstract}

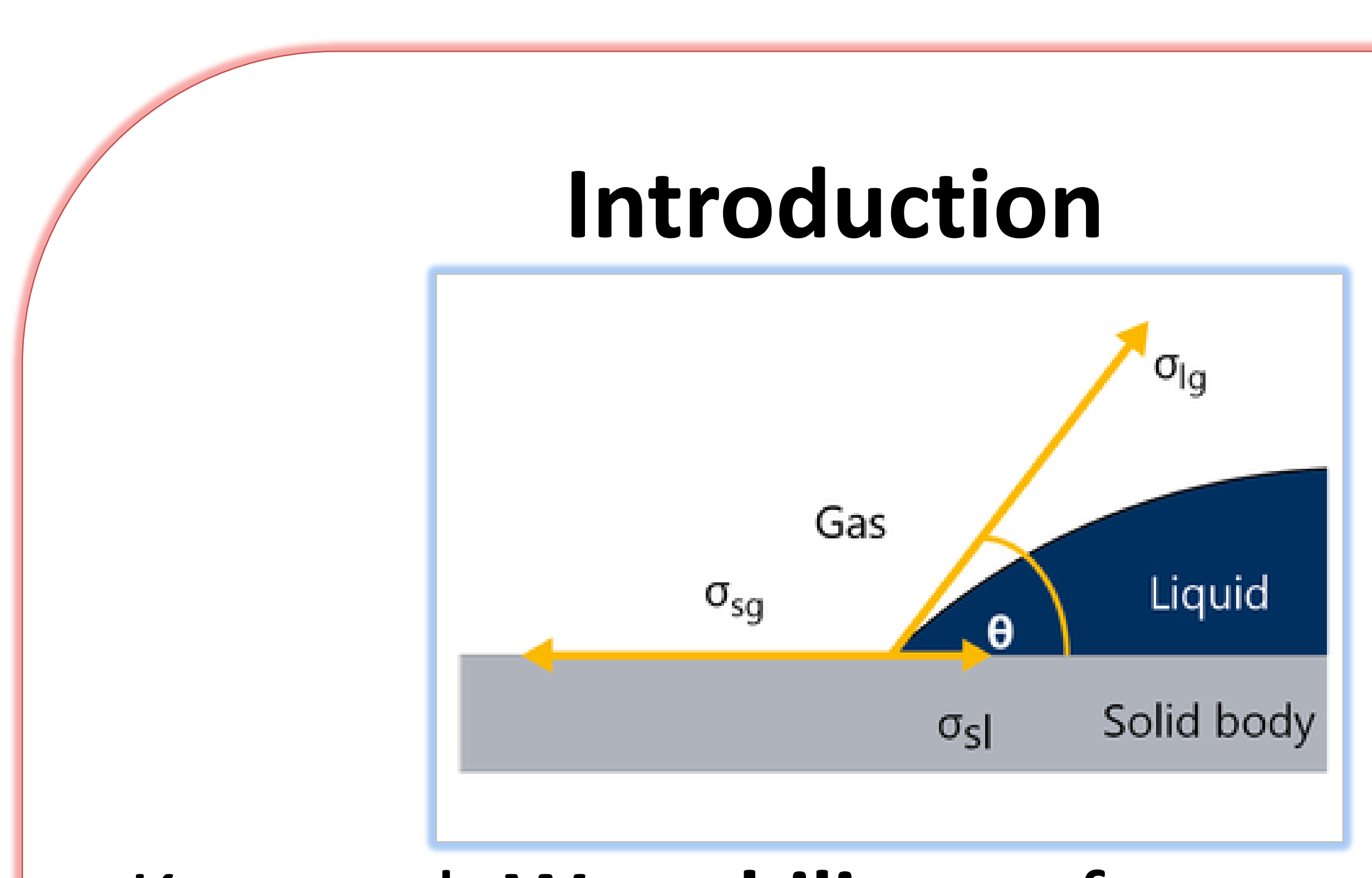

Keyword: Wettability: refers to the interaction between fluid and solid phases where the liquid phases can be water, oil or gas

Surface Tension: the tension of the surface film of a liquid caused by the attraction of the particles in the surface layer by the bulk of liquid, which tends to minimize surface area.

In the oil industry it is very important to have a water wet condition on the rock face in order to extract oil.

\section{Methodology}

We used the Cahn Dynamic Contact Angle Analyzer DCA 315 analyzer which, is an instrument used to measure the surface properties such as surface tension of solid and liquid samples by using the Wilhelmy technique.
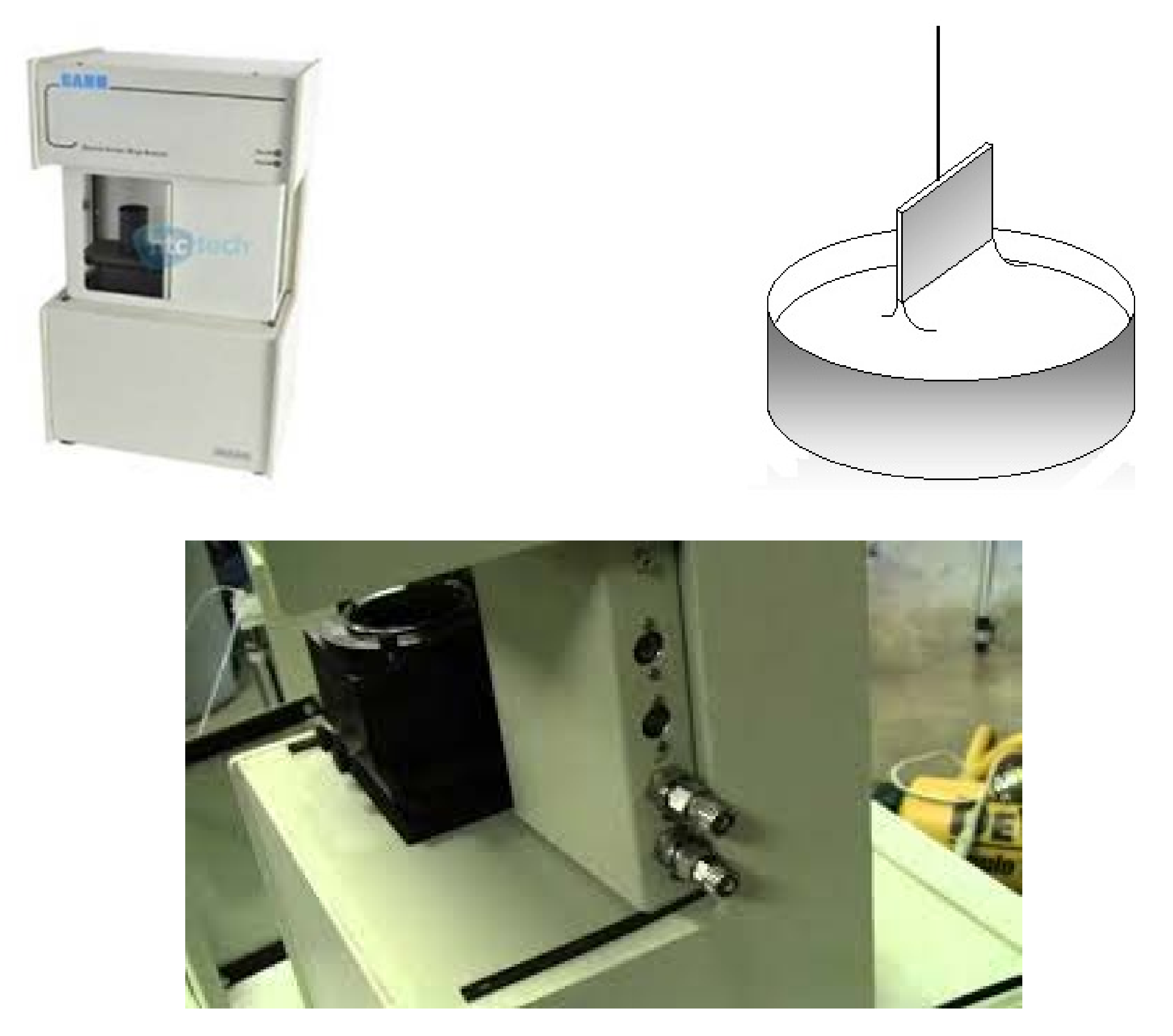

\section{Results}

The Effect of Different CaCl Saturations on WetSol Gro Surfactant's Surface Tension

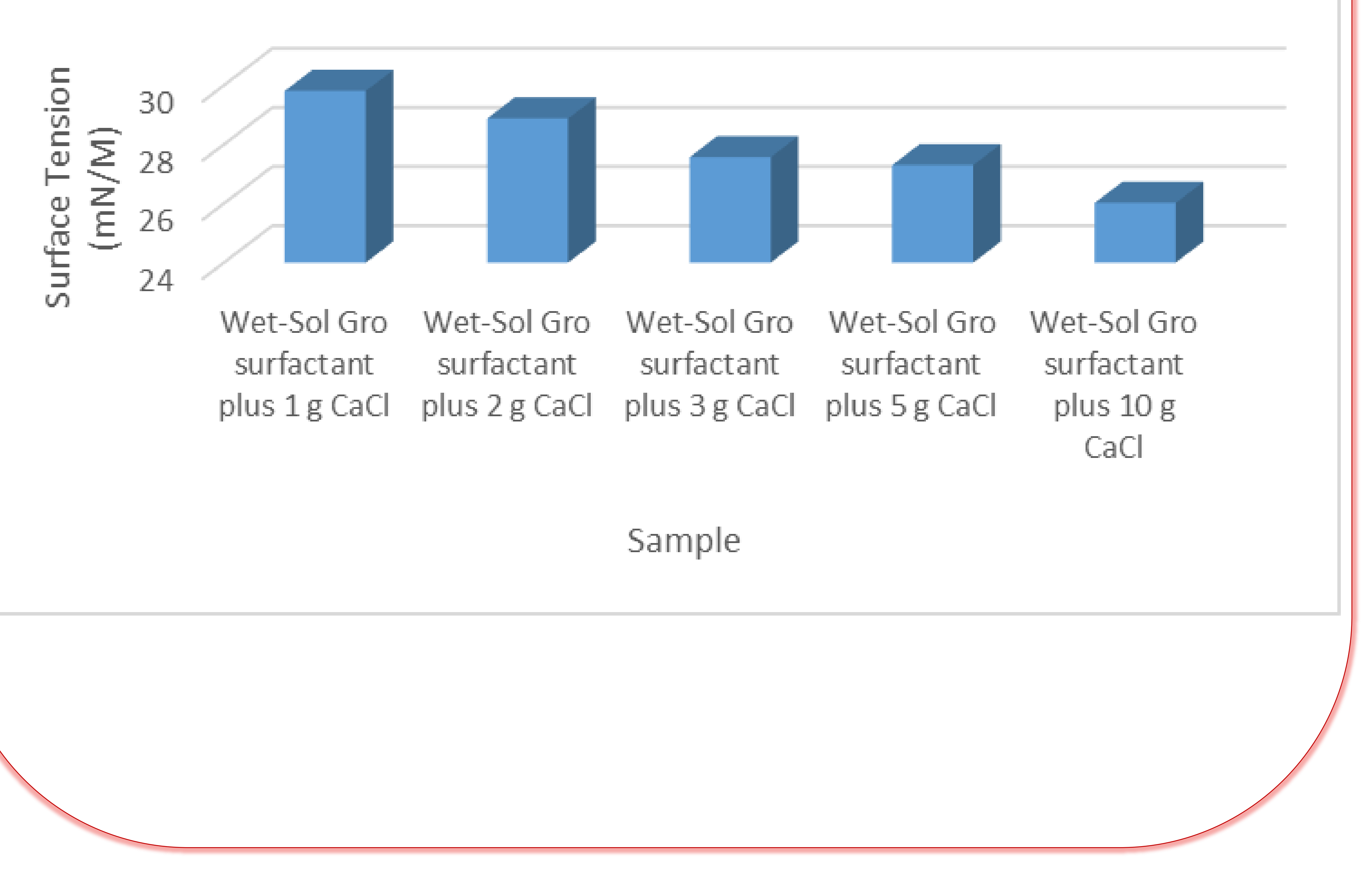

\section{Conclusion}

As seen in the results, the effect of brine on surfactant brings about significant changes in the surface tension as the weight of different salts are added. Another determinant of the affectivity of the application surfactant in oil extraction is the brine concentration of the reservoir. Acknowledgements. Dr. Mahmoud Elsharafi and Dr. Magaly Rincón-Zachary and the EURECA committee 